\title{
POLÍTICAS PÚBLICAS E PRÁTICA DESPORTIVA DE ALTO RENDIMENTO NO BRASIL E PORTUGAL
}

\section{Public policy and practice sport high performance in brazil and portugal}

\author{
Jairo Antônio da Paixão ${ }^{1,2,3}$, Janaina Garcia Sanches ${ }^{4}$, Denise de Souza Destro² \\ ${ }_{1}$ Programa de Pós-Graduação em Ciência do Desporto - Universidade de Trás-os-Montes e Alto Douro - UTAD - Portugal; \\ ${ }^{2}$ Faculdade de Minas - FAMINAS - Muriaé - MG \\ ${ }^{3}$ Faculdade Governador Ozanam Coelho - FAGOC - Ubá - MG. \\ ${ }^{4}$ Programa de Pós-Graduação em Educação - Universidade Federal de Minas Gerais - UFMG
}

\begin{abstract}
Resumo: Neste trabalho procuramos analisar, comparativamente, se o desempenho esportivo de Brasil e Portugal nas olimpíadas de 2004 pode estar relacionado ao incremento de políticas públicas elaboradas por ambos os países com vistas ao fomento do esporte de alto rendimento nível nacional e internacional. Nesse sentido, focalizamos as nossas análises não apenas nos desempenhos obtidos (classificações) desde os Jogos Olímpicos de 1980, mas também nas respectivas políticas públicas que possivelmente tenham sido empreendidas nesse período nos países mencionados.

Palavras-chave:
\end{abstract}

Abstract: In this work we try to analyse, comparatively, if the sporting performance of Brazil and Portugal in the last Olympiads can be connected to the growth of public politics prepared by both countries with sights to the incitement of the sport of high profit to level national and international. In this sense, we focus our analyses you do not punish in the obtained performances (classifications) from the Olympic Games of 1980, but also in the respective public politics that possibly have been undertaken in this period in the mentioned countries.

Key words:

Aceito em 10/02/2009 - Rev. Educ. Fís. 2009 Jun: 145: 37-43. Rio de Janeiro - RJ - Brasil

\section{INTRODUÇÃO}

Uma breve análise na trajetória dos atletas/equipes dos países participantes nos Jogos Olímpicos nos remete aos "Jogos de Atenas" 2004, nos quais Brasil e Portugal realizaram, reconhecidamente, as suas melhores campanhas na história das olimpíadas da era moderna ${ }^{(1)}$. No caso do Brasil - com quatro ouros, três pratas e dois bronzes conquistados -, ainda que estivesse longe de superar marcas mundiais, nunca se ouviu tantas vezes o hino nacional tocando nas cerimônias de premiação. Nesta mesma linha, Portugal obteve nesta mesma edição dos Jogos Olímpicos, o melhor conjunto de resultados referente às suas participações em competições desta natureza. Para além das três medalhas (duas de prata e uma de bronze), os participantes portugueses alcançaram mais 10 classificações até ao $8^{\circ}$ lugar em seis modalidades ${ }^{(1)}$. Esses dados nos sugerem que algo de substancial em relação ao fomento no esporte de rendimento nesses dois países deve ter sofrido reorientações que resultaram em maior visibilidade e projeção internacional em termos de resultados, podendo, inclusive, ser conseqüência de políticas públicas desenvolvidas por seus respectivos Governos conforme a proposição de Carvalho(2), os resultados esportivos por um determinado país são geralmente considerados uma indicação do estado de desenvolvimento do esporte em si mesmo e ou da própria nação em foco na comparação internacional. Este sentido de avaliação é normalmente adotado pela mídia em diferentes países. Trata-se também 
de um critério definidor de políticas governamentais em geral.

O GRÁFICO 1 demonstra o desempenho de Brasil e Portugal em termos de participação e classificação nos Jogos Olímpicos.

\section{GRÁFICO 1}

DESEMPENHO DE BRASIL E PORTUGAL JOGOS OLÍMPICOS 1920 A 2004.

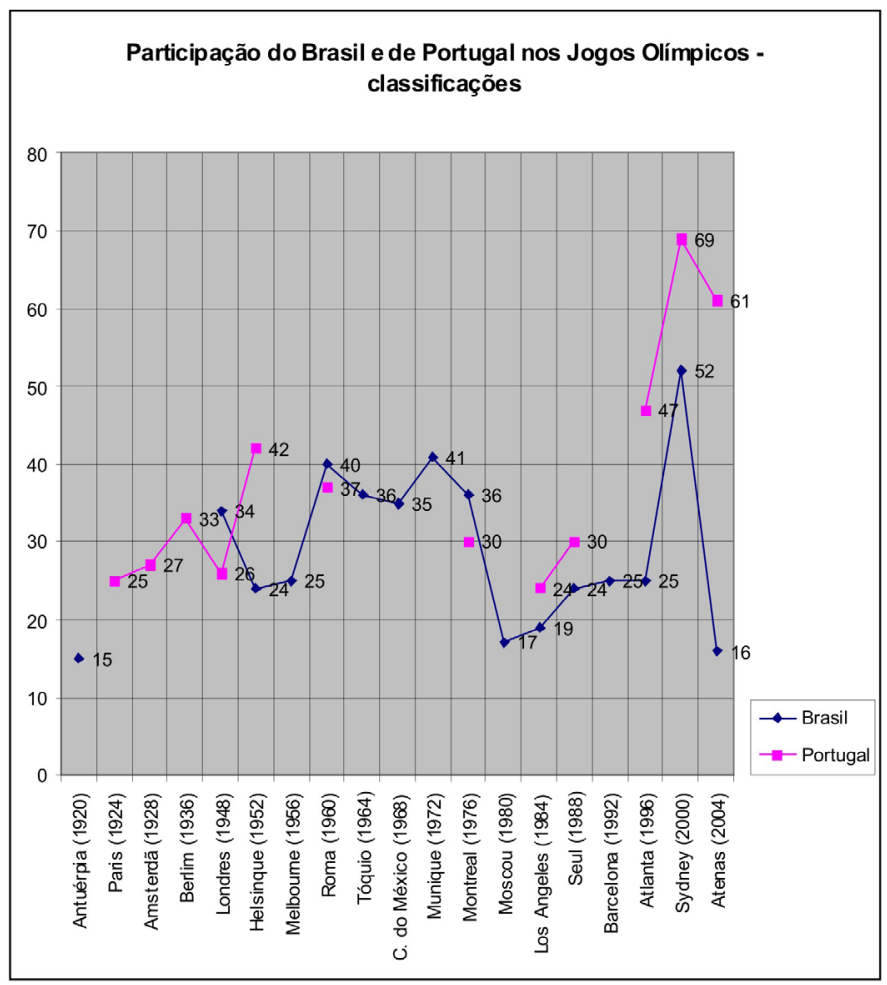

Pode-se dizer, a partir das informações do GRÁFICO 1, que o Brasil vem marcando participou de todas as Olimpíadas a partir de 1920, à exceção de 1928, em Amsterdã, devido à crise financeira que o país enfrentava na referida época. Entretanto, é a partir de 1980, nas Olimpíadas de Moscou, que o Brasil vem obtendo as suas melhores participações em termos de classificação geral, com exceção das Olimpíadas de Sydney, na qual a sua participação foi tida como a mais decepcionante da história. Nessa Olimpíada, especificamente, o Brasil não obteve nenhuma medalha de ouro. As poucas conseguidas se restringiram às de prata e bronze. Promessas como Dayane dos Santos (Ginástica Artística), Rodrigo Pessoa (Hipismo) e o Vôlei masculino não confirmaram seu favoritismo, frustrando a população brasileira e fazendo com que o Governo Federal, através do antigo Ministério da Educação e do Desporto repensasse sua "responsabilidade" enquanto órgão público e fomentador de políticas públicas para o esporte.

Por outro lado, pode-se perceber que Portugal classificou-se menos vezes que o Brasil e, na maioria das suas participações, teve desempenho inferior em relação ao nosso país. Apesar de ambos os países terem realizado as suas melhores participações nas olimpíadas de Atenas, em 2004, observa-se que Portugal ainda apresentou um desempenho inferior ao do Brasil no tocante à classificação geral e ao número de medalhas. Este fato nos chama à atenção tendo em vista que Portugal é considerado como um dos países que possui alto índice de desenvolvimento humano $(\operatorname{IDH})^{(3)} \mathrm{e}$, nesse sentido, teria condições de realizar maiores investimentos na promoção do esporte de rendimento. Já o Brasil, mesmo com participação superior à de Portugal nestes Jogos, é tido como um país de médio desenvolvimento humano. Em função desse entendimento, deparamos-nos aí com um verdadeiro paradoxo, uma vez que um país mais pobre, em termos de desenvolvimento humano, tem apresentado melhor desempenho que um país mais desenvolvido nesse mesmo critério. Contudo, temos que levar em consideração as diferenças na extensão territorial e no tamanho da população de ambos os países, pois, isso representa uma vantagem para o Brasil no que diz respeito à possibilidade de descobrimento de talentos esportivos.

Nesse sentido, somos instigados a refletir sobre os caminhos percorridos por estas duas nações para alcançarem suas melhores conquistas nas últimas olimpíadas, realizadas em Atenas no ano de 2004.

Considerando-se que ambos os países melhoraram seus índices olímpicos nessa última competição, reportamo-nos à questão do desenvolvimento esportivo que, necessariamente, 
deve ter ocorrido tanto no Brasil quanto em Portugal, principalmente, em relação ao talento de seus atletas de alto-rendimento, como também a uma possível reorientação das políticas públicas que envolvem as diferentes modalidades esportivas desses países.

No caso do Brasil, a questão do talento no esporte tem se constituído como um dos temas mais relevantes e, ao mesmo tempo, um dos mais complexos no âmbito das ciências do desporto e das políticas públicas para o desenvolvimento do esporte ${ }^{(4)}$. A busca de talentos para o esporte nacional privilegia, sobretudo, os padrões técnicos e performativos dos indivíduos. Contudo, considerando a história social do nosso país, percebe-se nesta busca de talentos, diversos fatores que concorrem para a redução das oportunidades do indivíduo em participar deste seleto grupo de atletas que conseguem despontar nas competições. Dentre estes fatores, merecem destaque a situação econômica da família ou do praticante da modalidade esportiva, número reduzido de equipes de alto rendimento, locais inadequados para o treinamento e falta de oportunidade para que a criança ou o jovem descubra em qual modalidade esportiva teria melhores condições para o desenvolvimento de seu potencial.

Em função dessas diferenças econômicas e sociais a que estão submetidos às crianças e jovens brasileiros no tocante à prática do esporte e, conseqüentemente, à sua profissionalização, tem-se, em nosso país, um discurso que vem desde as décadas de 60/70 do século passado, permeando o consenso da população nacional: a meritocracia. Ghiraldelli Jr ${ }^{(5)}$, já chamava a atenção para essa questão ao mencionar a Educação Física Competitivista enquanto tendência que realizava o culto do atleta-herói, aquele que a despeito de todas as dificuldades chegou ao pódio e que a noção de potência olímpica ou potência esportiva, era disseminada com o intuito de promover o desporto representativo, capaz de trazer medalhas olímpicas para o país(5). Esse ideal funcionava como analgésico social na medida em que os trabalhadores mantinham-se atrelados à prática de alguma atividade física ou até mesmo, participando em forma de espectadores.

A partir dessas considerações que configuram a trajetória do atleta no mundo esportivo, percebe-se que a Educação Física tratada no âmbito escolar é, potencialmente, um dos caminhos para se descobrir possíveis atletas, configurando-se como o principal lócus para o desenvolvimento de talentos esportivos nacionais, representando uma fase que antecede a preparação dos futuros campeões olímpicos. Tal discurso, como narra a história da Educação Física brasileira e como componente curricular na escola(6,7) remonta a uma Educação Física quase que absolutamente submissa aos códigos de uma instituição esportiva, na qual a padronização técnica dos gestos esportivos e a exigência de performatividade atlética, entre outros elementos, passaram a definir os conteúdos deste componente curricular na educação básica. Este direcionamento é bem visualizado na década de 70 , nos discursos dos atletas, ex-atletas, técnicos, dirigentes e jornalistas esportivos em relação à possibilidade de se criar um quadro de futuros atletas olímpicos através das aulas de Educação Física escolar ${ }^{(8)}$.

Com os resultados apresentados aquém do esperado nas Olimpíadas de Sidney em 2000, o governo brasileiro, através dos Ministérios da Educação e do Esporte, inicia uma série de discussões sobre o referido fracasso atribuindo ao fato de a Educação Física escolar não se dedicar ao ensino do esporte visando à formação de novos atletas. Em função disso, propõe o Projeto Esporte na Escola em 2001, o qual se caracterizou pela distribuição de materiais esportivos para as escolas públicas, subjugando os interesses e as funções sociais da escola em detrimento das 'necessidades' do esporte de alto rendimento(9). 
No contexto atual, há uma retomada deste discurso, porém com outras roupagens, por meio de incentivos e investimentos previstos em políticas públicas pelo atual Ministério dos Esportes como evidencia Souza $\mathrm{Jr}^{(8)}$, através de projetos que objetivam descobrir talentos na escola como os Jogos Estudantis (Nacional) - Olimpíada Colegial: projeto do COB junto com o Ministério da Educação; Núcleos para incentivo esportivo - Centros Olímpicos de Desenvolvimento de Talentos: iniciativa do COB para construção de uma sede para o projeto de descobrimento de talentos esportivos no meio infantil, mais especificamente, entre crianças matriculadas nas escolas de redes públicas estaduais; Locais para formação de especialistas em Esporte - Centro Olímpico de Estudos do Esporte: ação do COB para formar profissionais especializados nas diversas áreas do esporte (psicologia, medicina, marketing), além de professores de Educação Física; Incentivos à produção científico-acadêmica na área do Esporte - $2^{a}$ edição do Prêmio Brasil Esporte: série de publicações realizadas pelo Ministério de Esporte e Turismo, cujo objetivo é estimular o desenvolvimento de tecnologias que possam favorecer o esporte.

De acordo ainda com a Política Nacional de Esportes $^{(10,11)}$, outras ações ainda são explicitadas de responsabilidade do Governo Federal através do atual Ministério dos Esportes, que estimulam a prática esportiva em todo o país como o Programa 'Segundo Tempo', que visa crianças e adolescentes em situação de vulnerabilidade social, oferecendo a eles, além da prática esportiva, alimentação, cultura e acesso ao conhecimento; o Programa 'Esporte e Lazer na Cidade', que busca criar a igualdade de oportunidade esportiva e de lazer para a população, favorecendo a integração social e o Programa 'Bolsa-atleta', que dá uma ajuda de custo a maiores de 12 anos até para os atletas de categoria olímpica e paraolímpica.

Apesar de ações mais específicas a respeito do esporte na escola, nota-se que há, nos espaços escolares, um estado de total precariedade com que os professores de Educação Física ministram suas aulas, principalmente em segmentos públicos de ensino no Brasil. Falta de materiais esportivos e não-esportivos, espaços inadequados para a prática dos esportes, dificuldade de formação continuada, pouco ou nenhum apoio da comunidade escolar, dentre outros, são alguns dos problemas mais recorrentes da Educação Física enquanto disciplina escolar, que inviabiliza, de certa forma, a implementação de programas esportivos oriundos de órgãos oficiais governamentais.

Partindo das argumentações acerca do reconhecimento das características e princípios do esporte olímpico/de alto rendimento, bem como das diferentes vertentes de abordagens pedagógicas para o ensino da Educação Física escolar no contexto atual, o esporte, segundo a abordagem Crítico Superadora, precisa estar presente nas aulas de Educação Física escolar como um conteúdo a ser apreendido pelos alunos, o qual deve ser organizado e estruturado pedagogicamente de forma a ser entendido, apreendido, refletido e reconstruído enquanto conhecimento que constitui o acervo cultural da humanidade, de forma a possibilitar sua constatação, sistematização, ampliação e aprofundamento(12). Nesse sentido, vê-se limitada a possibilidade de se desenvolver ou mesmo descobrir talentos esportivos nessa perspectiva pedagógica pelos professores de Educação Física que a seguem, sem contar as condições materiais inadequadas para o fomento do esporte nos estabelecimentos escolares já mencionadas anteriormente. Porém, segundo a Política Nacional de Esportes ${ }^{(11)}$, o esporte escolar é aquele praticado na escola tanto no âmbito das aulas de educação física na educação básica e superior quanto aquele desenvolvido em atividades extracurriculares. O documento ainda afirma que o ensino na escola não deve orientar-se, apenas, para a formação de uma futura elite esportiva, o que não significa a eliminação da possibilidade de desenvolvimento de atletas a partir do ensinamento 
das práticas esportivas na escola. A esse respeito, a estrutura do esporte nacional deve contemplar os locais e meios adequados - que não a escola - para a realização de um trabalho de base assentado numa visão de futuro e num programa especializado na formação de pequenos iniciantes.

Contudo, acreditamos que a escola pode se tornar um espaço que atenda às diferentes abordagens para o trabalho em Educação Física constituindo-se também como um espaço que fomente o desenvolvimento do esporte, ou seja, o trabalho que busque desenvolver nas crianças e nos jovens as competências e habilidades necessárias caso desejem trilhar uma trajetória no esporte de alto rendimento.

Esta situação reforça algo amplamente conhecido no mundo esportivo: não há desempenho de ponta sem investimentos sérios e contínuos. E, infelizmente, a falta de recursos financeiros continua sendo o maior obstáculo para o desenvolvimento do esporte no país.

A partir dessas considerações, percebe-se que a história do Brasil em termos de políticas públicas para o esporte prevê a formação de atletas para a representação do país em eventos esportivos e não, simplesmente, a massificação do esporte enquanto prática cultural e social.

Assim como ocorre no Brasil, em Portugal, as políticas desportivas que visam descobrir talentos no esporte de alto rendimento lançam suas bases no âmbito educacional, ou seja, no público jovem que se encontra inserido de forma regular da educação básica ao ensino superior. $E$ para se atingir esta meta, como evidencia o documento final do congresso do desporto realizado na cidade de Estoril, em 18 de fevereiro de 2006(13) as políticas educativas e sociais no desporto de Portugal deverão valorizar a Educação Física e o desporto no projeto educativo das escolas, do $1^{\circ}$ ciclo do ensino básico até o ensino superior. O referido documento ressalta ainda o esforço na articulação entre escolas, autarquias, comunidades e clubes, visando à otimização dos meios e espaços desportivos.

Desta forma, notá-se que os programas do governo português mantêm consonância com a política de esportes preconizada pela Organização das Nações Unidas, a qual visa o acesso ao esporte das camadas desprivilegiadas da população portuguesa. Nesse contexto, o esporte desempenha uma série de papéis como incremento aos programas ligados à saúde, educação e garantia de acesso e permanência do aluno no ensino fundamental ${ }^{(14)}$.

Como foi mostrado no GRÁFICO 1 que evidencia o desempenho de Brasil e Portugal nos Jogos Olímpicos, Portugal não só apresentou desempenho inferior como ainda classificou-se menos vezes que o Brasil. Esta situação representa uma questão preocupante para Portugal, como consta no documento do congresso de desporto em 2006, no qual “...Portugal não deverá resignar-se a ocupar, entre os países da União Européia, o último lugar em termos dos índices da prática desportiva...".

A posição ocupada por Portugal no ranking mundial em termos de desempenho desportivo no contexto atual, pode ser a resultante de ações localizadas no passado. Como exemplo, na década de 30 , em termos de políticas públicas voltadas para o desporto em geral e, em especial, para o desporto escolar, o próprio Estado proibia veementemente a prática desportiva nas escolas públicas de forma oficial como o expressa o Decreto $n^{\circ} 21: 106$ de 16 de Abril de 1932. Conforme o Fórum Olimpico de Portugal, tal situaçao começa a mudar a partir da década de 70 com o estabelecimento do Movimento Desportivo Voluntário, que visava sobretudo a criação de clubes desportivos escolares no ensino médio, como ainda a Lei de Bases do Sistema Desportivo (LBSD). Somente a partir do final da década de oitenta, através do Despacho 4/ME/88 de 12/1/88 as políticas públicas voltadas para o desporto em geral e para o desporto escolar alcança um progresso efetivo. A Lei de Bases do 
Sistema Desportivo (LBSD) propicia ao país um desporto escolar com personalidade própria no âmbito do Sistema Desportivo e subordinado aos quadros específicos do Sistema Educativo ${ }^{(15)}$.

Percebe-se em Portugal um aumento considerável em relação aos índices olímpicos. Neste sentido, faz-se oportuno ressaltar, por exemplo, as ações empreendidas pelo Ministério da Presidência, que se encontra a frente a área do desporto, o qual vem mobilizando recursos e esforços no sentido de preparar o segmento jovem da populaçao portuguesa para as competiçoes olímpicas. A efetivaçao destes esforços se dão por meio do Comitê Olímpico de Portugal através de projetos como o "Projecto Pequim 2008" inciado no ano de 2005. Diante do êxito que vem sendo alcançado, o referido Comitê já confirmou à imprensa a intenção de prosseguir tais açoes com vista aos Jogos Olímpicos de Londres de 2012.

\section{CONSIDERAÇÕES FINAIS}

Tendo em vista que ambos os países (Brasil e Portugal) fizeram, reconhecidamente, a sua melhor campanha/participação na história dos Jogos Olímpicos modernos, é possível inferirmos que tal êxito esteja relacionado ao fomento proporcionado pelas políticas públicas neste setor.

A partir dos dados pesquisados foi possível verificar que os essas nações utilizam formas diferenciadas no que se refere a mobilizar o segmento jovem de suas respectivas populações, buscando atingir o âmbito escolar por meio de propostas e projetos, bem como o fomento à formação de atletas e equipes de alto nível. Ainda que as iniciativas governamentais no desenvolvimento do desporto de rendimento não atendam em sua totalidade os atletas em potencial que alimentam o sonho olímpico, verificam-se ações específicas dos governos de Brasil e Portugal em relação às políticas públicas para o esporte, que indubitavelmente vem contribuindo para uma nova situação desses países no cenário do esporte de alto rendimento. Nesse contexto, os Jogos Olímpicas ainda constituem momento ímpar no qual é oportunizado à uma nação apresentar ao mundo os resultados de esforços empreendidos no âmbito desportivo.

\section{REFERÊNCIAS BIBLIOGRÁFICAS}

1. Vicente, L. Memória virtual. [homepage na internet]. [acesso em 20 julh. 2008]. Disponível em:http:// memoriavirtual.wordpress.com/2004/08/11/jogosolimpicos-2004-atenas/

2. Carvalho, A. M. Atlas do Esporte no Brasil: Atlas do esporte, educação física, atividades físicas, saúde e lazer. Rio de Janeiro: Shape, 2005.

3. Indice de Desenvolvimento Humano. [homepage na internet]. [acesso em out. 2007]. Disponível em: http:// pt.wikipedia.org/wiki//DH.

4. Gonzalez, F. J.; Fensterseifer, P. E. Dicionário crítico de educação física. ljuí: Unijuí, 2005.

5. Ghiraldelli J., P. Educação Física Progressista: a pedagogia crítico-social dos conteúdos e a educação física brasileira. São Paulo: Loyola, 2004.

6. Castellani F. I. Educação Física no Brasil: a história que não se conta. Campinas,SP: Papirus, 1988.

7. Darido, S. C. Educação Física na Escola: questões e reflexões. Rio de Janeiro: Guanabara Koogan, 2003.

8. Souza J. M. A Educação Física no Currículo Escolar e o Esporte: (im)possibilidade de remediar o recente fracasso esportivo brasileiro. [homepage na internet]; [acesso em 27 out. 2007]. Disponível em http://www.revistas.ufg.br/index. php/fef/article/viewFile/72/72 .

9. Melo, M. P. Esporte e Juventude Pobre: políticas públicas de lazer na vila olímpica da maré. Campinas, SP: Autores Associados, 2005.

10. Brasil. Ministério da Educação. [homepage na internet]. [acesso em 15 jun. 2008] Disponível em: http://portal.mec. gov.br/.

11. Brasil. Ministério do Esporte. Política Nacional do Esporte [homepage na internet]. [acesso em 19 jun. 2008]. Disponível em: http://portal.esporte.gov.br/ 
12. Soares, C. Metodologia do Ensino da Educação Física. São Paulo: Cortez, 1992.

13. Portugal, Documento Final do Congresso do Desporto. Estoril 2006.[homepage na internet]; [acesso em 17 set. 2008]. Disponível em http://www.portugal.gov.pt/Portal/PT/ Governos/Governos_Constitucionais/GC17/Ministerios/ PCM/MP/Comunicacao/Programas_e_Dossiers/20060218_ MP_Doss_Congresso_Desporto.htm.

14. Instituto de Desporto de Portugal. Notícias: ONU Proclamou Ano Internacional do Desporto e da Educação Física. [atualizada em 2006, acesso em 21 jan. 2008]. Disponível em: http://www.idesporto.pt/noticias_detalhes. asp?Rid=193.
15. Forúm Olímpico de Portugal. desporto e desenvolvimento humano.[homepage na internet]. [acesso em 08 out. 2007]. Disponível em: http://forumolimpico.org/?q=node/98.

\section{Endereço para correspondência:}

Jairo Antonio da Paixão

Rua Afonso Pena, 220

Bairro centro

Viçosa, MG.

Tels (31) 38913783 e (31) 91258292

Email: jairopaixao2004@yahoo.com.br 